\title{
Erratum to: Origin of flooding water through hydrogeochemical identification, the Buenos Aires plain, Argentina
}

\author{
M. M. Alconada-Magliano • J. R. Fagundo-Castillo • \\ J. J. Carrillo-Rivera · P. G. Hernández
}

Published online: 8 September 2011

(C) Springer-Verlag 2011

Erratum to: Environ Earth Sci (2011) 64:57-71

DOI 10.1007/s12665-010-0817-7

Unfortunately, the acknowledgment was not included in the original publication. The acknowledgment section is given below:

Acknowledgments The support during a sabbatical stay of J.J. Carrillo-Rivera in the Hungarian Geological Institute in Budapest by the National Autonomous University of Mexico and of the Dirección General de Asuntos del Personal Académico (DGAPA) is kindly acknowledged.

The online version of the original article can be found under doi:10.1007/s12665-010-0817-7.

M. M. Alconada-Magliano

CISAUA (MAA-UNLP) y FCAgFs,

Universidad Nacional de La Plata, Buenos Aires, Argentina

J. R. Fagundo-Castillo · P. G. Hernández

Centro Nacional de Medicina Natural y Tradicional,

Havana, Cuba

J. J. Carrillo-Rivera ( $₫)$

Instituto de Geografía, Universidad Nacional Autónoma de

México, México, Mexico

e-mail: joeljcr@igg.unam.mx 